\title{
Severe genital laceration in a 7-year-old girl caused by rape
}

\begin{abstract}
A 7-year-old girl was admitted to N'Djamena Mother and Child hospital on December, 18th 2015 for vaginal pain and bleeding after rape.

Physical examination: The vulva was soiled with fresh blood. The exam discovered a second degree tear: perinea skin, vagina mucosa, hymen, and perinea muscle are torn.

The suture of laceration was performed under general anesthesia respecting plan of mucosa, muscle and skin. Infectious diseases screening was negative. The postoperative course was simple with discharge at the $2^{\text {nd }}$ postoperative day. The examination performed one month later showed a good evolution.
\end{abstract}

Keywords: perinea laceration, young girl, rape, vagina mucosa, hymen, HIV, hepatitis $\mathrm{B}$, anal sphincter
Volume 5 Issue 7 - 2016

Gabkika BM,,', Foumsou L,,2 Kaimba BM, ${ }^{3}$ Sile NS, ${ }^{2,4}$ Ndilbe NS, ${ }^{1,2}$ Richard DI

IDepartment of Genecology obstetric, N?Djamena Mother and Child hospital, Chad

${ }^{2}$ Human Health Sciences Faculty of N?Djamena University, Chad ${ }^{3}$ Department of surgery, Hospital la Renaissance, Chad ${ }^{4}$ Department of pediatrics, N? Djamena Mother and Child hospital, Chad

Correspondence: Foumsou Lhagadang, Human Health Sciences Faculty of N'Djamena University, University of N'Djamena - Chad, B.P II I 7 N'Djamena, Tel 00235662863 89, Email foumlhaga@gmail.com

Received: May 24, 2016 | Published: December 06, 2016

\section{Introduction}

Non obstetrical genital injuries are gradually becoming a common cause of genital injuries. ${ }^{1}$ These injuries are described as laceration of the skin and other soft tissue structure which in women separate the vagina from the anus. ${ }^{2}$ Mechanisms leading to perinea laceration are: coitus, and trauma. ${ }^{2,3}$ Non consensual sex has been reported to be a possible cause of this type of injuries, but its contribution to traumatic lesions of the female genital tract is not well known. ${ }^{2,4}$ The issue of genital injury and its association with rape is contentious. ${ }^{4}$ Many cases of genital lacerations concerning young people have been reported mainly in context of rape or trauma. We report a case of young girl 7 years aged with genital laceration after rape.

\section{Case report}

A girl aged of 7 years was admitted in N'Djamena Mother and Child hospital (Chad) on December, 18th 2015 for vaginal pain and bleeding after rape. The onset of symptoms was 2 hours marked by vagina pain and bleeding occurring after the rape of the young by a 20 years old man. The young girl was raped by his neighboring house when hers parents was out. After the odious act he ran away. When parents were back, they discovered their daughter complaining of abdominal pain and bleeding. The admission examination noted a conscious patient, complaining of abdominal pain and bleeding. The general examination revealed a well nourished patient weighing 20 $\mathrm{kg}$ with a height of $116 \mathrm{~cm}$, conjunctival mucosa well colored with a blood test showing haemoglobin to be $12.4 \mathrm{~g} / \mathrm{dl}$, a blood pressure $100 / 60 \mathrm{mmHg}$, radial pulse $75 \mathrm{bpm}$ and a temperature of $37.2^{\circ} \mathrm{C}$.

\section{Physical examination}

The vulva was soiled with fresh blood. The exam discovered a second degree tear: perinea skin, vagina mucosa, hymen, and perinea muscle are torn. The anal sphincter is intact (Figure 1). The remainder of the physical examination was unremarkable.

The suture of laceration was performed under general anesthesia respecting plan of mucosa, muscle and skin. Different kind of violet braided absorbable suture (2/0 for mucosa and hymen, 1 for muscle and $1 / 0$ for the skin). The haemostatic control was good.

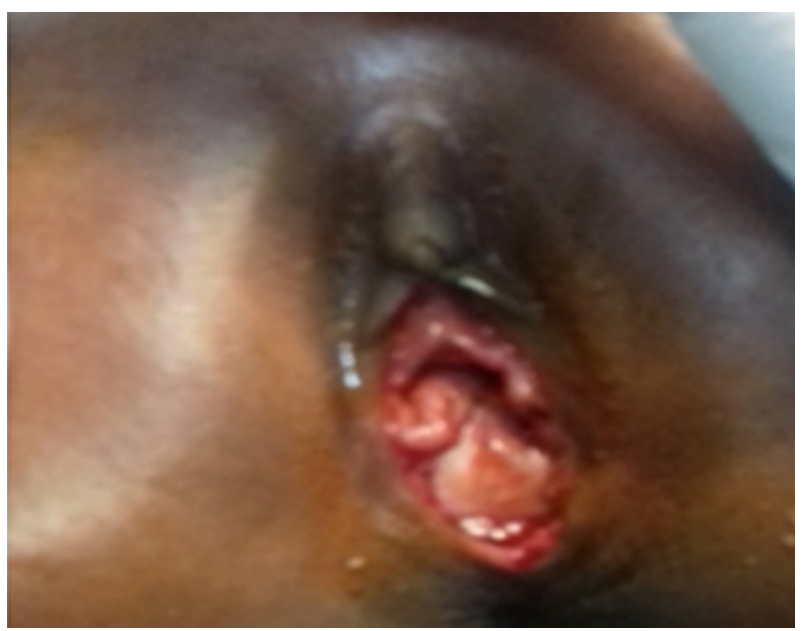

Figure I genital laceration before suture (credit bray).

Antibiotic cover was given (using amoxicillin) and paracetamol was used for pain. Infectious diseases screening was negative for HIV, hepatitis B and C, TPHA/VDRL, Chlamydia Trichomatis, Mycoplasmas Hominis, Neisseria Gonorrhea. As recommended in Chad anti HIV drug for preventing was given (using Efavirenz). The postoperative course was simple with discharge at the $2^{\text {nd }}$ postoperative day. The examination performed one month later showed a good evolution (Figure 2). HIV and hepatitis B screening performed 3 months later were negative.

\section{Discussion}

Recent reports showed that sexual violence occurs throughout the world. These reports come mainly from India and Africa countries. Diverse reasons are found: sexual desire, vengeance, witchcraft practice, humiliation. 


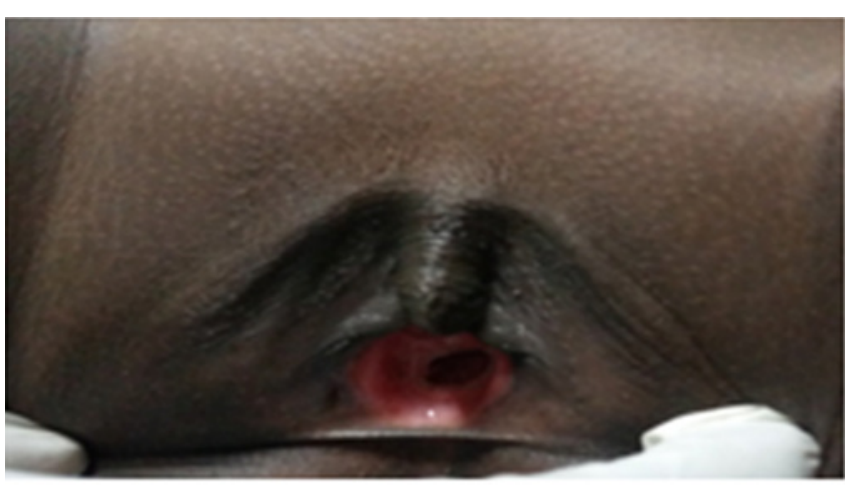

Figure 2 Photo of the girl 3 months after suture of laceration (credit bray).

Sexual violence includes rape, defined as physically forced or otherwise coerced penetration. ${ }^{5-7}$ This act is condemned by our society and rapist escape avoiding judicial condemnation. Like in this case, the there is not legitimate reason for sexual violence. The aim is to satisfy sexual desire.

Prior studies reported that young women are usually found to be more at risk of rape than older women, one-third and two-thirds of all victims of sexual assault are aged 15 years or less. ${ }^{6,8}$ Forced vagina penetration causes physical and psychological complication for the patients. Main Gynaecological complications reported are minor. Severe gynecological complications remain possible: these include vaginal tear, bleeding, pelvic pain, and infection (further).

Genital lacerations describe in this case are imputable to the disproportion of the adult 'sex with the minor' vulva. The mechanism explaining these lacerations is the physical observation of content and container. When content is longer or larger than container it causes the rupture of the container. Then the genital lacerations noted in this case are the consequence of the disproportion. The lacerations was mainly posterior, one can explains this by the anatomic configuration of the woman. The posterior part of the perinea is recognized as a weak point.

In the same way, Geist ${ }^{9}$ reported previously that genital laceration are more commonly located posterior and to the right. The diagnosis of the second degree of perinea tear was obvious with the mucosa, vagina perinea and hymen discovered during exam. The management of severe lacerations sometimes requires sutures aiming to stop hemorrhage and to repair tissues. The suture of laceration was performed respecting mucosa, muscle and the skin. Different kinds of absorbable violet braided were used. Thus mucosa was sutured first the following step were the reconstruction of hymen and the suture of muscle and the skin. The hymen reconstruction was for social reason. In some area of Chad, virginity is an honor for the family. The lost of the integrated of hymen is not accepted by some families. The step of suture respecting mucosa, muscle and skin is like what described by Jeng, ${ }^{10}$ Parant ${ }^{11}$ and Berkenbaum. ${ }^{12}$

Sexually transited diseases can be spread in the endemic area when the sex was forced and without condom. In case of rape, the context doesn't often allow the use of condom. The abrasions or and cuts resulting for forced vagina penetration can facilitate the entry of the virus, when it is present through the vaginal mucosa. ${ }^{13}$ Thus the possibilities for transmission of infectious diseases exist for minor and severe laceration. The best way to prevent these infections diseases is the screening and the preventive treatment. Our attitude for screening HIV and hepatitis B was appropriate. The use of antiretroviral drugs following the rape was reasonable. This was confirmed by the last screening performed 3 months later that was negative for HIV.

\section{Conclusion}

Young girl perinea tear following rape is uncommon situation. Surgical treatment is required when the laceration is severe. The screenings of infectious diseases have to be done aiming to protect and give preventive drugs.

\section{Acknowledgements}

None.

\section{Conflicts of interest}

The authors declare no conflict of interest.

\section{Funding}

None.

\section{References}

1. Tchounzou R, Chichom-Mefire A. Retrospective Analysis of Clinical Features, Treatment and Outcome of Coital Injuries of the Female Genital Tract Consecutive to Consensual Sexual Intercourse in the Limbe Regional Hospital. Sex Med. 2015;3(4):256-260.

2. Abasiattai AM, Etuk SJ, Bassey EA, et al. Vagina injuries during coitus in calabar: a 10 years review. Niger Postgrad Med J. 2005;12(2):140144 .

3. Bhagat M. Coital injury presenting in a 13 year old as abdominal pain and vaginal bleeding. Pediatr Emerg Care. 1996;12(5):354-355.

4. Ezechi OC, Fasubaa OB, Dare FO. vagina injury during coitus at IleIfe:a 16 year review. Nig J Med. 2009;9:16-18.

5. Jewkes R, Vundule C, Maforah F, et al. Relationship dynamics and adolescent pregnancy in South Africa. Soc Sci Med. 2001;52(5):733744.

6. Matasha E, Ntembelea T, Mayaud P, et al. Sexual and reproductive health among primary and secondary school pupils in Mwanza, Tanzania:need for intervention. AIDS Care. 1998;10(5):571-582.

7. Buga GA, Amoko DH, Ncayiyana DJ. Sexual behaviour, contraceptive practice and reproductive health among school adolescents in rural Transkei. S Afr Med J. 1996;86(5):523-527.

8. Acierno R, Resnick H, Kilpatrick DG, et al. Risk factors for rape, physical assault, and post-traumatic stress disorder in women:examination of differential multivariate relationships. J Anxiety Disord. 1999;13(6):541563.

9. Geist RF. Sexually related trauma. Emerg Med Clin North Am. 1988;6(3):439-466.

10. Jeng CJ, Wang LR. Vaginal laceration and hemorrhagic shock during consensual sexual intercourse. $J$ Sex Marital Ther. 2007;33(3):249-253.

11. Parant O, Reme JM, Monrozies X. Recent perinea obstetric laceration and episiotomy. Encycl Méd Chir (Elsevier, Paris), France, Obstétrique. 1999;5-078-A-10.

12. Berkenbaum C, Balu L, Sauvat F, et al. Severe vaginal laceration in a 5 -year-old girl caused by sudden hydro-distention. $J$ Pediatr Adolesc Gynecol. 2013;26(6):e131-e132.

13. Jenny C, Hooton TM, Bowers A, et al. Sexually transmitted diseases in victims of rape. $N$ Engl J Med. 1990;322(11):713-716. 